\title{
Judicial enforcement and the protection of the right to health and the environment. A Peruvian case
}

\author{
By Rocío Meza Suarez, Giessen*
}

\section{Introduction: A victory for La Oroya's long struggle}

On June 2006, Peru's highest court (the Constitutional Court) gave the Peruvian Ministry of Health 30 days to declare a health emergency and to put in place an emergency plan for the city of La Oroya, widely considered one of the most contaminated in the world ${ }^{1}$. La Oroya is home to a multi-metal smelter, (copper, lead, zinc, silver and gold) owned by the Doe Run Company.

In its precedent-setting ruling, the Court emphasised that the government is primarily responsible for protecting public health. The Court ordered the Ministry of Health to immediately provide health care for those harmed by contamination and to establish programs of epidemiological and environmental vigilance. It also noted that plans and studies underway are not proof of adequate government control, and that the authorities must take effective actions to produce concrete improvements. ${ }^{2}$

From the compliance and enforcement perspective, the case of La Oroya is not typical. Usually the citizen (or the private sector) is seen as the one who must comply with the regulations, and the government as the one who must enforce them. But, what happens when, as in the case of La Oroya, it is the citizen who must start the enforcement mechanism against the government, to force it to comply with the regulations and halt situations that endanger the public health and the environment?

\section{The antecedents: A public health crisis en La Oroya}

Doe Run Peru purchased the multi-metal smelting facility in 1997 , which is considered to be a huge source of heavy metal and sulphur dioxide emissions. ${ }^{3}$

* Meza Suarez, Rocío Mercedes, LL.M. (University of Kent at Canterbury). 2003-2005 lecturer at the Catholic University of Peru. Obtained in 2006 a scholarship from the Katholischer Akademischer Ausländer-Dienst (KAAD). Since then she is a Ph.D candidate at the University of Giessen, Germany. E-Mail: rociomeza@gmx.net

1 In 2006 the Blacksmith Institute launched the list of the World's Worst Polluted Places. According to this list, La Oroya is among the 10 most polluted. Available at http://www. blacksmithinstitute.org (accessed on November 2006).

2 "Peruvian court orders relief for victims of lead poisoning by US-Owned Smelter". Available at www.earthjustice.com (accessed on 20 November 2006).

3

La Oroya: Lead poisoning and the Doe Run lead smelter in Peru. Available at http://www.aidaamericas.org (accessed on 17 September 2006). 
La Oroya, located at an altitude of 3,700 meters in the Peruvian Andes, is surrounded by mountain peaks, making the area prone to temperature inversions that in turn trap the atmospheric contamination over the city ${ }^{4}$. Sixty-five percent of the population of Yauli Province, in which La Oroya is one of ten municipalities, lives below the poverty line ${ }^{5}$, and basic services are scarce. Many of the more than 30,000 inhabitants of La Oroya depend on the metal smelter as their primary source of income ${ }^{6}$.

Doe Run is to blame for severe public health problems in the poor city where it is located. ${ }^{7}$ Recent studies have demonstrated the extent of contamination and the serious risk to life and health that it poses, particularly to vulnerable groups, such as women, children and the elderly. Its effects cannot always be observed immediately, but are often irreversible. Respiratory problems caused by sulphur dioxide $\left(\mathrm{SO}_{2}\right)$ contamination and lead poisoning are particularly widespread. High concentrations of sulphur dioxide correlate with premature death, chronic respiratory illness, aggravation of asthmatic symptoms, and acute respiratory symptoms. Clinical studies have also revealed reduced pulmonary function and bronchial clearance rates from exposure to $\mathrm{SO}_{2}{ }^{8}$.

Lead poisoning is also a very serious problem in the city. Lead is particularly harmful to children, and there are countless studies showing that even exposure to low levels can cause decreased intelligence and physical development, as well as diminished neurological development and reduced hearing 9 . Lead compounds affect the blood, the nervous system, the reproductive system and the kidneys.

According to a 1999 study, $99.1 \%$ of the children in La Oroya suffered from lead poisoning while nearly $20 \%$ needed urgent hospitalisation. Even after seeing these shocking statistics the Ministry of Health took no action to treat the children, to limit exposure, or to educate the public about the health risks. It wasn't considered neither that the levels of

CEDHA, AIDA and Earthjustice, Petition to the Interamerican Commission on Human Rights requesting Emergency Precautionary Measures for La Oroya, Peru. Executive English Summary. Available at http://www.aida-americas.org/ (accesed on 13 december 2006).

5 Ministerio de Salud del Perú. Dirección Regional de Salud de Junín, Convenio MINSA DIGESA - Doe Run del Perú: Plan Operativo 2006 para el control de la población infantil y gestantes de contaminantes con indicadores biológicos en La Oroya Antigua y localidades seleccionadas de la Provincia de Yauli, La Oroya, 2006.

CEDHA, AIDA and Earthjustice, Petition to the Interamerican Commission on Human Rights requesting Emergency Precautionary Measures for la Oroya, Peru. Executive English Summary. Available at http://www.aida-americas.org/ (accesed on 13 December 2006).

La Oroya: Lead poisoning and the Doe Run lead smelter in Peru. Available at http://www.aidaamericas.org (accessed on 17 September 2006).

8 Barandiarán G., Alberto / Cederstav, Anna K., La Oroya cannot wait, Lima, 2002, p. 89 et seq. 
air contamination (including indoor contamination ${ }^{10}$ ) vastly exceed recommended international standards established by the WHO and Peruvian law ${ }^{11}$.

\section{How the case was brought before the court}

In December 2002, six citizens of La Oroya, backed by a Peruvian NGO, brought a Compliance Suit (Acción de Cumplimiento) to force the Ministry of Health to design and implement a Public Health Emergency Strategy as prescribed by the General Health Act Law 26842 and consequently: a) to take measures to treat those affected and protect vulnerable groups; b) to comply with health and air regulations, such as the establishment of a state of emergency in the city, according with Law 26842, article 105 and c) to establish epidemiological and environmental vigilance programs, according with Decree 074-2001PCM. As stated in article 200 inc. 6) of the Peruvian Constitution and article 66 of the Civil Procedural Code, the Compliance Suit can be brought against any authority or official who refuses to abide by a legal norm or administrative act. ${ }^{12}$

Although the Compliance Suit is included in the Peruvian Constitution in the Chapter "Constitutional guarantees", it does not protect directly a specific constitutional right or an aspect of the Constitution ${ }^{13}$, because, as we already explained, it can be brought in case any authority or official refuses to abide by a legal norm or administrative act. Nevertheless, the Court considered that this case was related not only to the control of the administrative inaction, but if such inaction endangered the right to health and to an adequate environment. If this were the case, although the compliance suit could not "directly" protect the rights to health and environment, it could give an "indirect" protection, as long as there is a clear, concrete and valid prescription included in a legal regulation or an administrative act that has an indissoluble link to the protection of the right.

The mission of the Court was then to find out if there was inaction of the Peruvian Government, and that if such inaction endangered the right to health and the environment. In order to analyse the ruling of the Court, firstly the content of the right to health and

10

AIDA - CEDHA - Earthjustice, Petition to the Interamerican Commission on Human Rights Requesting Emergency Precautionary Measures for La Oroya, Perú. English Executive Summary. A 2003 study of building interiors showed that $100 \%$ of the dwellings tested exceeded maximum recommended lead content levels, indicating that residents of La Oroya are exposed to significant contamination within their homes.

11 Atmospheric lead levels in La Oroya between January and August 2004 were four to five times the WHO-recommended levels, while levels of arsenic were measured at six to eight times the levels found in highly contaminated European cities. Company monitoring reports from 2004 indicated that cadmium levels, were 20 times the level recommended by the WHO. Sulphur dioxide levels in 2003 were two to four times greater than levels the WHO considers harmful, and consistently reach peak concentrations that generate significant human health impacts.

12 Tribunal Constitucional (Peru), Sentence from 12 May 2006, EXP. N. ${ }^{\circ}$ 2002-2006-PC/TC. Available at http://www.aida-americas.org (accessed on 17 October 2006).

13

Instituto de Defensa Legal et al., Manual del Sistema Peruano de Justicia, Lima, 2003, p. 247. 
environment and the duties of the State regarding its implementation willl be discussed from the international and national perspective. Then, the Court's ruling will be reviewed and it follows an analysis if there was inaction from the Peruvian Government, and if this inaction endangered the right to health and to an adequate environment.

\section{The human right to health and the environment}

\section{Definition of the right to health}

Health is difficult to define because it is a very subjective experience, varying geographically from one country or area to another. ${ }^{14}$ The first expression of this right in an international legal instrument came in the 1949 World Health Organisation (WHO) Constitution, which states that "The enjoyment of the highest attainable standard of health is one of the fundamental rights of every human being without distinction of race, religion, political belief, economic or social condition". 15

The conception of health had numerous attempts to define it, varying as to whether they include only physical, or physical as well as mental, or also even social well-being; and from more 'negative' or 'moderate' descriptions ('health' is the absence of disease' or 'the ability to function in society') to more 'absolute' ones ('health is a "positive" matter, or 'health is well-being). ${ }^{16}$ These attempts eventually culminated in the wide and rather absolute definition in the Constitution of the WHO:

"Health is a state of complete physical, mental and social well-being and not merely the absence of disease or infirmity". 17

Other international documents also offer a definition of the right to health. For example, the International Covenant of Economic, Social and Cultural Rights (ICESCR) states in Article 12.1: "The States Parties to the present Covenant recognize the right of everyone to the enjoyment of the highest attainable standard of physical and mental health". ${ }^{18}$ The Additional Protocol to the American Convention on Human Rights in the area of Economic, Social and Cultural Rights provides in article 10 (1): "Everyone shall have the right to health, understood to mean the enjoyment of the highest level of physical, mental and social well-being".

Toebes, B.C.A., The Right to Health as a Human Right in International Law, Oxford, 1999, p. 20.

World Health Organisation. Constitution. Available at http://whqlibdoc.who.int/hist/official_ records/constitution.pdf

Toebes (above Fn. 14), p. 21.

Preamble to the Constitution of the WHO as adopted by the International Health Conference, New York, 19-22 June, 1946; (Official Records of the World Health Organization, no. 2, p. 100) and entered into force on 7 April 1948.

Gruskin S. / Tarantola, D., Health and Human Rights. Francois-Xavior Bagnoud Center for Health and Human Rights, Working Paper No. 10, 2000. Available at http://www.cesr.org/ESCR/ hsphgruskin.pdf. 
Actually, the right to health grants a right to a number of health-related services, claims and freedoms, taking into account the available resources of a State and the health needs of its people. ${ }^{19}$ In order to improve the understanding of the right to health, it is necessary to clarify its normative content. As said by Toebes, two concepts play a particular role in this attempt: The scope and the core content. ${ }^{20}$

\section{Scope of the human right to health}

The scope of human right to health can be illustrated by the following definition: 'Every human being has the right to an environment with minimum health risks, and to have access to health services that can prevent or alleviate their suffering, treat disease, and help maintain and promote good health through the individual's life'. ${ }^{21}$ It is important to recognise the broader character of the right to health encompassing more than just a right to health care, ${ }^{22}$ but also, as acknowledged by the express wording of article 12.2 of the ICESCR ${ }^{23}$ and by the General Comment 14 to ICESCR, a wide range of socio-economic factors that promote conditions in which people can lead a healthy life, or 'underlying preconditions' of health, such as access to safe and potable water and adequate sanitation, food and nutrition, housing, healthy occupational and environmental conditions, access to health related education and information. ${ }^{24}$

\section{The core element of the right to health}

The core content consists of those elements that a state has to guarantee under any circumstances, irrespective of its available resources. ${ }^{25}$ To trace these elements it is necessary to find the minimum level of health individuals require to have a dignified life and to be adequately integrated into society. For that effect, Toebes suggests an overview of the elements of the scope of the right to health, to see which are most essential from a human

19

20

22

23

International Covenant of Economic, Social and Cultural Rights, article 12.2: 'The steps to be taken by the States Parties to the present Covenant to achieve the full realization of this right shall include those necessary for: (a) The provision for the reduction of the stillbirth-rate and of infant mortality and for the healthy development of the child; (b) The improvement of all aspects of environmental and industrial hygiene; (c) The prevention, treatment and control of epidemic, endemic, occupational and other diseases; (d) The creation of conditions which would assure to all medical service and medical attention in the event of sickness'. Available at http://www. unhchr.ch/

24

25

Office of the High Commissioner for Human Rights, The right to the highest attainable standard of health. E/C.12/2000/4, ICESCR General Comment 14. Available at http://www.unhchr.ch

Toebes (above Fn. 14), p 281-284. 
rights perspective, basing this approach on the policies designed by the WHO in its Health for All Primary Cares Strategies. ${ }^{26}$ These strategies identify the core content of the right to health from a policy perspective and stipulate a health baseline below which no individuals in any country should find themselves. Combining the elements of the scope of the right to health and the elements in WHO, the following components can be characterised as "core elements": Health care, including maternal child health care, immunisation against the major infectious diseases, appropriate treatment of common diseases and injuries, and essential drugs; as well as the underlying preconditions for health, such as adequate supply of safe water, basic sanitation and protection from serious environmental threats. ${ }^{27}$

\section{The obligations of the State in order to protect the right to health}

The general obligation in Article 2 of the ICESCR is 'to take steps, individually and through international assistance and co-operation, (...), to the maximum of its available resources, with a view to achieving progressively the full realization of the rights recognized in the present Covenant by all appropriate means'. The programmatic character of the ICESCR is, therefore, evident: This article, which set forth the 'principle of progressive realisation, ${ }^{28}$, does not set out rights which the parties have to implement immediately, but rather lists standards which they agree to promote and secure progressively, to the greatest extent possible, having regard to their resources. ${ }^{29}$

In that sense, the ability of the parts to fulfil the right to health will differ due to their varying economic resources. The different levels of economic development, combined with factors such as climatic conditions, imply that not all countries will enjoy an equivalent standard of health. The principle of progressive realisation means in this case that the right to health 'does not provide an absolute world standard but is rendered relative to the world health inequalities'. 30

This principle leads sometimes to problems due to the fact that, as it recognises variable standards of health, it becomes difficult to identify criteria to evaluate the decisions countries make on health policy. The progressive realisation still disturbs the right to health even under a minimum-core-obligations-approach, as we can realise from the gap that exists between these core-obligations and the actual condition of public health in the developing countries. However, the relativity of health standards allowed by this principle can-

Tomaševski, K., Health Rights in: Eide, A. / Krause, C. / Rosas, A. (eds.), Economic, social and cultural rights. A textbook, Dordrecht, 1995, p. 129.

27

28

29

30

Toebes (above Fn. 14), p. 347.

Fidler, D.P., International law and infectious diseases, Oxford, 1999, p. 184.

Robertson, A.H. / Merrills, J.G., Human Rights in the world, Manchester, 1996, p. 246.

Fidler (above Fn. 28), p. 184. 
not excuse inactivity, because, as described earlier, it requires progressive realisation within the parameters of available economic resources. ${ }^{31}$

Additionally, the tripartite typology of obligations assumes that the right to health does not only give rise to positive obligations to "protect" and "fulfill", but also includes negative obligations to "respect" services and to refrain from health-harming activities such as environmental pollution. ${ }^{33}$

\section{The environmental element and the right to health}

The recognition of the link between human rights, health and environment can be found already in the Stockholm Declaration (1972): "Man has the fundamental right to freedom, equality and adequate conditions of life, in an environment of a quality that permits a life of dignity and well-being, 34 .

Since then, various international legal instruments and decisions of human rights bodies have taken different rights-based approaches to this link. The first approach, closest to the Stockholm Declaration, understands environmental protection as a pre-condition to the enjoyment of internationally guaranteed human rights, especially the rights to life and health. The second rights-based approach, most common since 1992, instead of viewing environmental protection as an essential element of human rights, views certain human rights as essential elements to achieving environmental protection. We have as example, the Rio Declaration on Environment and Development, that formulates a link between human rights and environmental protection largely in procedural terms, declaring in Principle 10 that access to information, public participation and access to effective judicial and administrative proceedings, should be guaranteed because "environmental issues are best handled with the participation of all concerned citizens, at the relevant level." These procedural rights are thus adopted in environmental texts in order to have better environmental decision-making and enforcement. For the third, most recent approach, the right to a healthy environment is an independent substantive human right, and the links between environmental protection and human health are indivisible and inseparable. Examples of this are found mainly in national law and in regional human rights and environmental treaties. Most formulations of the right to environment qualify it by words such as "healthy", "safe", or "clean". 35

Ibid. p. 184 and 197.

32 Toebes, B.C.A., 'Towards an improved understanding of the international human right to health' (1999) 21 Human Rights Quarterly 661-679.

Toebes (above Fn. 14), p. 347.

34

Principle 1 of the Declaration of the United Nations Conference on the Human Environment (Stockholm Conference), UN Doc. A/CONF/48/14/REV.1

35

Shelton, Dinah, Human rights, health and environmental protection: Linkages in law and practice.

A Background Paper for the WHO, 2002. 
The ICESCR does not explicitly recognise the right to a clean environment as such. Paragraph 2(b) of Article 12, however, requires State parties to "improve all aspects of environmental and industrial hygiene." Although the meaning of the term 'environmental hygiene' remains unclear, in recent years it has been interpreted broadly so as to refer to those aspects of human health and disease that are determined by factors in the environment. ${ }^{36}$ Environmental health is thus, generally regarded to be covered by the term "environmental hygiene." This is because the protection of the environment entails indirectly but necessarily the protection of human beings, insofar as the object of environmental law and hence of the right to a healthy environment is to protect human being assuring them an adequate living environment. ${ }^{37}$ On the other hand, recognition of a clean environment as a separate human right can be found in some documents of regional organizations, such as the African Charter of Human and Peoples' Rights and the Additional Protocol to the American Convention on Human Rights in the area of Economic, Social and Cultural Rights, ${ }^{38}$ and in many national legislations.

Nevertheless, the existence of an international right to a healthy environment remains disputed in international law. For some scholars a human right to environment has emerged or is emerging in customary international law. For other authors ${ }^{39}$, no independent right to a decent environment has yet become part of international law. ${ }^{40}$ This could be the reason why the rights to life and to health are sometimes invoked for the protection against environmental degradation. Although not set forth in the treaties' texts, or in the two General Comments on article 6 of the International Covenant on Civil and Political Rights $(\mathrm{ICCPR})^{41}$, it has been argued by several authors that a healthy environment is protected by the right to life. On the other hand, several articles on the right to health, such as Article 12

The European Charter on Environment and Health is the first international effort to define environmental health and to set up international mechanisms for its promotion, as environmental health reaches far beyond the mandates and means of both national and international health authorities. K. Tomaševski, "Environmental Rights" in A. Eide / C. Krause / A. Rosas (eds.), Economic, social and cultural rights. A textbook, Dordrecht, 1995, p. 268.

Kiss, Alexander, International human rights law and environmental problems, in: Brown Weiss, E. (ed.), Environmental change and international law: New challenges and dimensions, Tokyo, 1992.

The African Charter recognizes the rights of all peoples to a "generally satisfactory environment favorable to their development." The Additional Protocol to the American Convention on Human Rights provides in its Article 10: "1. Everyone shall have the right to live in a healthy environment and to have access to basic public services. 2. The States Parties shall promote the protection, preservation and improvement of the environment."

39

40

41

See Birnie, Patricia / Boyle, Alan, International Law \& the Environment. London, 2002, p. 254 et seq.

For example, Birnie and Boyle elaborated a list of objections to the notion of an autonomous human right to a decent environment. Fidler, D.P. (above Fn. 28), p. 257-258.

CCPR General Comment 6 (Sixteenth session, 1982): Article 6: The Right to Life, A/37/40 (1982) 93; and CCPR General Comment (Twenty-third session, 1984) Article 6: Nuclear Weapons and the Right to Life. Office of the High Commissioner for Human Rights. 
of the ICESCR, include States' obligations regarding a clean environment, as we have already seen.

\section{The right to health and the environment in Peruvian legislation}

According to the Constitution, ratified international treaties are considered as part of the national law. The Government of Peru has ratified a range of international and regional human rights treaties recognizing the right to health and other health-related rights, such as the ICESCR, the ICCPR, the International Convention on the Elimination of All Forms of Racial Discrimination, the Convention on the Elimination of All Forms of Discrimination Against Women, the Convention on the Rights of the Child, the American Convention on Human Rights, the Additional Protocol to the American Convention on Human Rights in the area of Economic, Social and Cultural Rights, among others. ${ }^{42}$

The Peruvian Constitution recognizes, in article 7, the right of everyone to the protection of their health and the family's and the community's health. Article 9 emphasizes the responsibility of the State in relation to developing national health policy, and the responsibility of the executive branch for designing and administering its implementation, in a decentralized and pluralistic manner so as to assure equal access to health services for all. On the other hand, the General Health Act 26842 states: "The protection of health is of public interest. It is a duty of the State to regulate, safeguard and promote it. (...) Every person has the right to the protection of health according to the legislation. (...) Public health is primarily the responsibility of the State (...). It is a responsibility of the State to promote the conditions that guarantee an adequate coverage of health services in acceptable terms of safety, opportunity and quality. This responsibility cannot be renounced." 43

Additionally, the Constitution and the domestic legislation offer protection to healthrelated rights such as the right to a healthy environment. Article 2.22 of the Constitution states that every person has the right " (...) to the enjoyment of an equilibrated environment, adequate to the development of his life". According to the Constitutional Court, the content of this right has two elements: a) the right to enjoy an equilibrated environment and b) the right to the preservation of that environment. ${ }^{44}$ The General Health Act states that " $(\ldots)$ Health legislation is of public order and regulates health matters and the protection of the environment in relation with public health." 45 "The Health Authority must take the necessary measures to reduce and control health risks derived from environmental factors. When

Hunt, Paul, Right of everyone to enjoyment of the highest attainable standard of physical and mental health. Report submitted by the Special Rapporteur on the right of everyone to the highest attainable standard of physical and mental health, Addendum: MISSION TO PERU E/CN.4/2005/ 51/Add.3 4 February 2005.

General Health Act 26842, Preliminary Title, Articles II, II, IV, VI.

44 Constitutional Court (Peru), in the case Mining Royalties EXP. N. 0048-2004-AI/TC.

45

General Health Act 26842, Preliminary Title, Article IX. 
pollution implies risk or damage to human health, the Authority shall take the indispensable prevention and control measures, in order to stop the actions or facts that originate those risks and damages". 46

Of course, there is still a number of shortcomings in the legislative framework in relation to the right to health. Paul Hunt, the Special Rapporteur on the right to health, noted that the Peruvian Constitution does not incorporate the right to health in the chapter of Fundamental Rights, but in a separate chapter (Economic and Social Rights). This distinction does not reflect the principle reaffirmed at the World Conference on Human Rights (1993) that all human rights must be treated in a fair and equal manner. Additionally, Mr. Hunt recommended formulating a comprehensive health policy and strategy designed to address "inequity, inequality, discrimination and the situation of those living in poverty. 47

It is clear that, despite the shortcomings, there is not a lack of legislation in Peru. Although it is necessary to improve the policies and strategies to make health more available to all sectors of society, but we can conclude that the Peruvian domestic legislation offers protection to the right to health and to other human rights closely linked to the right to health, such as the right to a healthy environment.

\section{The ruling of the Court: The Peruvian Government failed to comply with its own regulations}

According to the Constitutional Court's ruling, the omissions of the Peruvian government in the implementation of health and environmental requirements were:

\section{Non-compliance with its Obligations under the General Health's Law}

Articles 103, 105 and 106 of Law 26842 state that the Ministry of Health must establish environmental standards and take measures to minimise and control the health risks caused by environmental agents. Nevertheless, according to the Court, the compliance with this obligation has been only partial and insufficient. Seven years have passed since the Ministry of Health knew about the contamination in La Oroya, but it did not adopt the necessary measures. Furthermore, the government didn't design and implement a plan to address the State of Emergency, including developing a strategy to protect vulnerable groups and undertaking epidemiological and environmental monitoring programs.

\section{2. $\quad$ Non-compliance with its obligations under air quality laws}

The government didn't elaborate the baseline diagnosis of the air quality in La Oroya. This document is the basis for the further elaboration of the Air Quality Action Plan, according with Article 11 of the Decree 074-2001-PCM, Environment Air Quality Standards Law. 


\section{Failure to declare a State of Emergency}

Article 23 in the National Environment Air Quality Standards Law requires the Ministry of Health to declare a state of emergency when air pollution significantly exceeds recommended levels. Declaring a state of emergency would enable the government to take a series of immediate steps to help protect public health, however the government failed to implement such actions.

\section{Inaction that endangers the right to health}

\section{General context of omissions in the implementation of health and environmental requirements.}

The Peruvian government didn't provide adequate basic health care in La Oroya. According to the General Directorate of Environmental Health (DIGESA), the child mortality in the city is $20 \times 1000^{48}$, and there is a deficit of health infrastructure and coverage of $47,2 \%$. The only health facilities in the city lack proper diagnostic equipment and medicines to deal with common health problems. Furthermore, access to these facilities is restricted to people who are officially employed and thus part of Peru's social security program, or to those who can independently afford to pay for medical treatment. ${ }^{49}$ On the other hand, the Peruvian government didn't provide adequate sanitation: For example, there is a deficit in the of sewage disposal service of $53,2 \%$.

\section{Specific inaction invoked in the compliance suit}

The government, not complying sufficiently with the duties included in the legislation, didn't protect citizens from a serious environmental threat and this resulted in a serious health emergency. The health emergency situation in La Oroya required prompt action from the State and immediate response by the courts. Nevertheless, it wasn't until two years later, in April of 2005, that a Lima Civil Court ordered the Ministry of Health and DIGESA to implement concrete measures to protect the population. However, instead of complying with the court order, the government appealed the ruling thus further delaying action. ${ }^{50}$ Ignoring the situation and postponing solutions, the government exposed the La Oroya's residents to unnecessary and irreparable harm.

Although the Ministry of Health had undertaken some of its duties to control and prevent health and environmental harms, those measures were only partial and insufficient. The court said that the compliance suit has as aim to protect the efficacy of the norms and

DIGESA, Informe de la DIGESA en atención al fallo del tribunal constitucional relativo a la contaminación del distrito de la Oroya, Lima, 2006.

AIDA - CEDHA - Earthjustice, Petition to the Interamerican Commission on Human Rights Requesting emergency Precautionary Measures for La Oroya, Perú. English Executive Summary.

Ibid. 
the administrative acts. It shouldn't be aimed only to assess the formal compliance of the mandate included in the legislation or in the administrative act, but also to assess its effective compliance. In that sense, it was clear to the Court that there was inaction from the government because it did not comply effectively with its duties, and that this inaction endangered the right to health and to an adequate environment in La Oroya.

\section{The perfect equation to protect public health and environment}

\section{Good legislation, compliance and enforcement}

This case shows that having the adequate legislation is not the complete solution for the protection of public health and the achievement of environmental quality. Although the Peruvian legislation is clear regarding the actions that the government must take in this respect, the development of legislation involving legal requirements that must be met is only a first step. The next step, compliance (the implementation of legal requirements) is indispensable to achieving the goals envisioned by laws.

As public health and the environment will be protected only if environmental requirements get results, we need another component: enforcement (the set of actions that governments or others take to achieve compliance within the regulated community and to correct or halt situations that endanger the environment or public health). This is due to the fact that, as compliance is not necessarily automatic, it usually involves efforts to encourage and compel the changes in behaviour needed. ${ }^{51}$

\section{Enforcement mechanisms}

Enforcement mechanisms can be classified into informal and formal mechanisms. Informal responses (such as phone calls; site visits, warning letters, and notices of violations) advise what violation was found, what should be done to correct it, and by what date. The goal of informal action is to bring the violator into compliance or to initiate formal legal process. They do not penalize but can lead to more severe response if they are ignored. ${ }^{52}$

Formal enforcement mechanisms are backed by the force of law and are accompanied by procedural requirements to protect the rights of the individual. Formal mechanisms are either civil or criminal. Civil actions may be either administrative (i.e., directly imposed by the enforcement authority) or judicial (i.e., imposed by a court or other judicial authority) ${ }^{53}$. They could be inspections, orders, judicial or administrative procedures, and sanctions or remedies. Civil judicial enforcement actions are formal lawsuits before the courts. According to the separation of powers, at least one independent judicial institution

U.S. Environmental Protection Agency. Principles of Environmental Enforcement. Chapter 1 Available at http://www.inece.org/enforcementprinciples.html.

52

Ibid., Chapter 7

53

Ibid. 
is empowered to guarantee the implementation, due application and impartial execution of the laws. ${ }^{54}$ Some nations with civil enforcement authorities rely exclusively on civil judicial actions to enforce environmental laws. Other nations have adopted both administrative and judicial mechanisms to carry out civil enforcement.

Enforcement can include not only direct government actions to verify and secure compliance, like inspections, preventive orders and prosecution, but also indirect actions, like publicly releasing non-compliance information or providing information about enforcement procedures. The more indirect means have gained ground in developed countries. Many tasks involved in enforcement have been transferred to the regulated community, for example, through monitoring and reporting requirements and the promotion of environmental audits. In addition, traditional sanction-oriented enforcement actions (such as fines, closure of facilities, suspension or cancellation of permits, imprisonment and the cost of cleaning up pollution) are increasingly preceded by negotiated efforts to bring violators into compliance. Another development is the increasing involvement of citizens in the enforcement process, through consultations, access to information and legal actions, ${ }^{55}$ like in the case of La Oroya.

\section{Enforcement difficulties}

In many countries in Latin America the struggle for competitiveness and export-oriented growth may increase pressure on governments to restrain enforcement procedures in economic sectors like agriculture, logging, and mining, which are resource and pollution intensive. ${ }^{56}$ Dependence on those sectors may impede enforcement against them when they fail to comply with public health and environmental legislation, both linked in many cases. The Inter-American Commission on Human Right recognised that although the American Convention does not prevent nor discourage economic development, requires that it takes place under conditions of respect for the rights of individuals and that, while the right to development implies that each state may exploit its natural resources, the absence of regulation, inappropriate regulation or a lack of enforcement of norms may create serious environmental problems which translates into violations of rights protected by the Convention ${ }^{57}$.

Rest, Alfred, "Enhanced Implementation and Enforcement of International Environmental Laws by the Judiciary". In: The Law of Energy for sustainable Development. Eds: Adrian J. Bradbook, Rosemary Lyster, Richard L. Ottingen and Wang Xi. IUCN Academy of Environmental Law and Research Studies, Cambridge, 2005.

Paquin, Marc / Sbert, Carla, Towards Effective Environmental Compliance and Enforcement in Latin America and the Caribbean, November 2004. Unisféra International Centre. Available at http://www.unisfera.org/

57 Ibid.

Inter-American Commission on Human Rights, Report on the situation of Human Rights in Ecuador, 1997, at 89. 
The lack of empirical understanding of enforcement is also potentially problematic because an environmental standard that is in theory designed to protect public health and the environment may fail to accomplish that goal if enforcement is dominated by political calculations, mainly when it is the government who must comply ${ }^{58}$. Other common problems related to monitoring, compliance and enforcement are commonly insufficient social value attached by the public, understaffing of the institutions responsible for enforcing, shortcomings in judicial enforcement and lack of funds. ${ }^{59}$

\section{Parallel efforts to public enforcement}

As institutional enforcement capacity cannot be quickly attained in case of structural development problems and the absence of a culture of transparency and accountability, there are other ways such as public participation, information and entrepreneurial creativity that can be considered a parallel effort. ${ }^{60}$ The cooperation of the private sector has been the object of innovative mechanisms in recent years. In addition, in order to extend involvement to all citizens, countries have been creating consultation mechanisms and other judicial, quasijudicial and administrative procedures that enable citizens to play an active role in the development and enforcement of environmental laws and policies. ${ }^{61}$ Private enforcement can complement or even sometimes, substitute for public enforcement.

\section{Judicial enforcement: an effective citizen's tool against Government non- compliance?}

As we have seen, citizens and non-government groups may become involved in enforcement by using formal enforcement mechanisms to bring actions against violators or against the government. Citizens have the chance to pursue better environmental quality by bringing legal action against a public authority entrusted with responsibility for implementing the laws, to force it to comply with legislative or constitutional requirements. ${ }^{62}$

A civil judicial enforcement action was used in the case of La Oroya: The Compliance Suit was brought by citizens against the authority who refused to abide a legal norm. This action is not directly aimed to protect environment and health, but it was successfully used

58

Firestone, Jeremy, Enforcement of pollution laws and regulations: An analysis of forum choice, in: The Harvard Environmental Law Review Vol. 27 Number 1, 2003, p.105-176.

59

60

61

62

Tietenberg, Tom, Private enforcement of Environmental regulations in Latin America and the Caribbean. An effective instrument for Environmental Management? Inter American Development Bank, Washington, D.C., June 1996. 
in this case. Although administrative enforcement is generally preferred as a first response (with exceptions) because judicial lawsuits are far more expensive, require more staff time and may take several years to complete, judicial enforcement is often still perceived as having greater significance and more power to deter potential violations and to set legal precedents. $^{63}$

\section{Conclusion}

It is obvious that the recovering of public health and a decent environment in La Oroya will not be easily and quickly achieved. In December 2006 the Peruvian Minister of Health declared: "If it were my decision, I would immediately close the Doe Run smelter." Of course, this would not be a solution for the problems that the city is experiencing. There is a group of inhabitants who defends the operations of the smelter. As previously said, sixtyfive percent of the population of Yauli lives below the poverty line, and it is logical that the citizens directly or indirectly economically linked to the company are afraid of losing their means of subsistence. In that sense, as affirmed in the Petition to the Anti-American Commission oh Human Rights requesting Precautionary Measures for La Oroya,

“(...) forcing the citizens of La Oroya to choose between their children's right to be healthy, and their means of subsistence through their employment with Doe Run is unacceptable given that there are numerous measures that the government could implement to drastically improve public health without requiring the closure of the smelter".

Nevertheless, the case of la Oroya is a clear example of the central role of the civil society from the perspective of health and environmental protection. Nowadays, mechanisms such as judicial procedures enable citizens to play an active role in the development and enforcement of health and environmental legislation. Although the more indirect means to secure compliance have been transferred to the regulated community and have been gaining ground in developed countries (such as monitoring and environmental audits), the increasing involvement of citizens in the enforcement process, through consultations, legal actions and access to information can be considered an outstanding development. ${ }^{64}$ The case of La Oroya is very important for a country like Peru, where citizens have become discouraged due to the ineffective role of their governments.

Additionally, this case offers an important lesson about the essential role that courts can play in enforcing regulation. The Sentence of the Court is considered a legal victory, not only for La Oroya, but because it sets a precedent for future cases. This has an enormous

U.S. Environmental Protection Agency, Principles of Environmental Enforcement, Chapter 7. Available at http://www.inece.org/enforcementprinciples.html. 
transcendence considering that in most nations, including developing ones, although basic environmental laws are in place, an enormous gap still exists between the law and what is actually happening on the ground. The well being of the people and the environment is dependent upon an acceptable and universally respected system of laws; that is, a system accepted by all the society, including the executive branch. The possible solutions are diverse but include judicial capacity building in human rights and environmental law. ${ }^{65}$ As affirmed in the Johannesburg Principles on the Role of Law and Sustainable Development: ${ }^{66}$

“(...) an independent Judiciary and judicial process is vital for the implementation, development and enforcement of environmental law (...) Members of the Judiciary, as well as those contributing to the judicial process at the national, regional and global levels, are crucial partners for promoting compliance with, and the implementation and enforcement of, international and national environmental law (...) the fragile state of the global environment requires the Judiciary as the guardian of the Rule of Law, to boldly and fearlessly implement and enforce applicable international and national laws, which in the field of environment and sustainable development will assist in alleviating poverty and sustaining an enduring civilisation (...)". 